\title{
O cuidado de si em Michel Foucault: um dispositivo de problematização do político no contemporâneo Marcel Maia Gomes, ${ }^{\text {Orcid, } \star ~ M a r c e l o ~ F e r r e r i, ~}{ }^{\text {Orcid }}$ Flávia Lemos ${ }^{\text {Orcid }}$ Universidade Federal de Sergipe, São Cristóvão, SE, Brasil
}

\section{Resumo}

O presente artigo tem por objetivo discutir a noção do cuidado de si apresentada por Michel Foucault em seus estudos acerca da civilização greco-romana, analisando como as práticas do cuidado para consigo e para com os outros - quando articuladas à dimensão ética e às práticas de liberdade - conduzem a uma problematização do político, naquilo que incide sobre o governo dos outros. Por outro lado, os escritos foucaultianos também relacionam o cuidado de si a uma postura ativa (ético-politica) do sujeito, caracterizando, assim, uma possibilidade de resistência ao biopoder - comumente atrelado às tecnologias de controle e vigilância dos corpos. Como referencial bibliográfico este artigo utiliza tomos da História da sexualidade, interligando-os aos cursos A hermenêtica do sujeito e O governo de si e dos outros, ministrados por Foucault no Collège de France, bem como a algumas de suas relevantes entrevistas e análises de comentadores.

Palavras-chave: cuidado de si; política; ética.

\section{Care oneself by Michel Foucault: a device problematization of political in contemporary}

\begin{abstract}
This article aims to discuss care oneself by Michel Foucault in his studies about the greco-roman civilization, analyzing how care practices to oneself and to others - when articulated the ethics dimension and practices of freedom - conduct to a questioning politics, in what concern about government of others. On the other hand, Foucault's writings also relate care oneself to an active stance (ethical-political) the subject, consisting, therefore, a possibility of resistance to biopower - commonly linked to control technologies and monitoring of subjects. As bibliographic references this article uses of volumes the History of Sexuality, linking them to courses The hermeneutics of the subject and The government of self and others, taught by Foucault at the Collège de France, as well as some his relevant interviews and analysis from commenters.
\end{abstract}

Keywords: care oneself; politics; ethics.

\section{Introdução}

Os últimos livros de Michel Foucault, a partir da publicação dos volumes da História da sexualidade e, posteriormente, os cursos apresentados no Collège de France, no início dos anos oitenta, trazem uma discussão um tanto diferenciada daquilo que se conhecia das obras deste escritor francês, geralmente enfatizadas pela História da loucura, as epistemes da arqueologia, as tecnologias políticas de regulação de corpos, bem como as relações microfísicas de saber-poder.

Com $A$ vontade de saber, Foucault (2009a), ao elaborar a discussão do dispositivo de sexualidade, prepara um terreno de estudos em torno do que nomeia biopoder - entendido como um conjunto de tecnologias de poder cuja preocupação se pauta em regular e gerir a multiplicidade de práticas que se fazem vitais aos homens (FOUCAULT, 2009a). Em O uso dos prazeres (FOUCAULT, 2009b), o dispositivo de sexualidade passa a ser apresentado através da contextualização da ética sexual dos gregos antigos, a qual era problematizada por meio de um exercício do pensamento, como uma relação entre o exercício da liberdade do sujeito, as formas de seu poder e seu acesso à verdade. Já no terceiro tomo da História da sexualidade: o cuidado de si, Foucault (1984) destina atenção aos dois primeiros

\footnotetext{
^Endereço para correspondência: Universidade Federal de Sergipe, Centro de Educação de Ciências Humanas, Departamento de Psicologia. Avenida Mal. Rondon, s/n, Jardim Rosa Elze - São Cristóvão, SE - Brasil. CEP: 49100000. E-mail: marcelmog@gmail.com, marceloferreri@uol.com.br, flaviacslemos@gmail.com
}

séculos da era cristã (período helenístico e românico), e a uma nova perspectiva de atuação dos casais, dos papeis políticos e deveres cívicos dos sujeitos.

A discussão em torno da noção do cuidado de si, trazida por Foucault, é então atravessada por práticas que circunstanciam uma estética da existência, e a vida do homem percebida como uma obra de arte. Na Antiguidade, os gregos pretendiam estilo às suas vidas, utilizavam técnicas para estilizar sua conduta, realizavam constantes trabalhos sobre si mesmos e uma constante reflexão sobre esses mesmos trabalhos, os quais incidiam no envolvimento de relações para com os outros, para com a prática da verdade e do franco falar. Entretanto, todo um plano de constituição do sujeito, suas escolhas de modos de viver, se realizava dentro um marco regido por princípios e cercado por limites que se impunham como condições.

A estilização das condutas, norteada pela noção do cuidado de si dos antigos, permitia uma reflexão moral e ética, na qual os sujeitos se encarregariam de estar cientes de suas práticas e exercícios de liberdade, além de uma constante atenção e prudência para lidar com funções políticas. Nesse sentido, o cuidado de si oferece subsídios de análises quanto às práticas políticas dentre os governos dos homens, naquilo que repercute, ao mesmo tempo, em um governo de si e/ou governo dos outros. 
Seguindo estas formulações de pensamento, o presente artigo $^{1}$ busca entrelaçar características dessa noção do cuidado de si, enquanto potencial de problematização política no contemporâneo. Ponderadas suas diferenças para com o cenário atual, o cuidado de si, quando articulado a questões éticas e de liberdade dos sujeitos, pode tornar-se ferramenta de enfrentamento a práticas e discursos políticos que recheiam nosso cotidiano de dispositivos de verdade e de biopoder, e têm como principal objetivo manter controladas as práticas dos sujeitos, restringindo suas vidas a escolhas (ou falsas liberdades) "previamente demarcadas", minando passo a passo suas vontades de sentirem-se livres - o que caracteriza, assim, um processo engessador de práticas e saberes, e normalizador da vida subjetiva dos indivíduos (GOMES, 2013).

Portanto, este artigo propõe analisar a noção do cuidado de si, desenvolvida por Foucault, como um dispositivo capaz de colocar sobre questão as práticas políticas contemporâneas, à medida que se percebe um sujeito ético-político de postura ativa para consigo e os outros.

\section{Cuidado de si em Michel Foucault}

Em seus estudos ${ }^{2}$ acerca da cultura greco-latina - do século V a.C. aos séculos IV-V d.C. - Michel Foucault se depara com temáticas inovadoras, se comparadas às suas pesquisas anteriores, o que marca uma passagem entre seus escritos de cunho arqueogenealógico para os estudos de questões éticas, atravessadas pelas temáticas do cuidado de si, das práticas de si, das técnicas de subjetivação, bem como o vínculo histórico entre subjetividade e verdade.

No curso de 1982, no Collège de France, intitulado $A$ hermenêutica do sujeito, Foucault (2010a) tem a preocupação de organizar sua aula inicial em duas grandes discussões que suas pesquisas evocavam. Em primeiro, apresentar um paralelo de diferenciações construídas acerca do princípio do cuidado de si (epiméleia heautoû) e do conhece-te a ti mesmo (gnôthi seautón), no esforço de demonstrar como, ao longo da história do pensamento filosófico, o conhecimento de si mesmo ganhava respaldo e privilégio, ao passo que marginalizava a noção greco-romana do cuidado de si, geralmente desconsiderada e esquecida na história tradicional dos grandes feitos da humanidade.

Em seguida, Foucault chama atenção para a problemática do cuidado de si na experiência ética grega, entre os séculos IV e II a.C., a qual se configurava em aproximação com o campo filosófico, associado a algumas práticas realizadas no sujeito e para consigo mesmo: como ritos de purificação, concentração da alma, práticas de resistência etc.

O cuidado de si estaria ligado a uma prática da espiritualidade, apresentando minimamente três princípios básicos: 1) entendia que a verdade jamais seria dada de pleno direito ao sujeito, por um simples ato de conheci-

${ }^{1}$ Este artigo é decorrente da dissertação de mestrado "O cuidado de si na redução de danos: uma análise histórica, política e ética, a partir de Michel Foucault", defendida em 2013 e vinculada ao Núcleo de Pós-Graduação em Psicologia Social da Universidade Federal de Sergipe. Em face ao pensamento de Foucault, esta pesquisa de mestrado propôs questionar se o discurso do cuidado de si presente nas propostas de redução de danos, direcionadas a usuários de drogas, seria condizente a uma dimensão ético-libertadora para com o usuário, ou a um imperativo moral do cuide-se no campo das práticas de saúde.

${ }^{2}$ Referem-se às publicações dos três volumes iniciais da História da sexualidade, bem como os últimos cursos no Collège de France, a partir de A hermenêutica do sujeito. mento; 2) demandaria a necessidade do sujeito se transformar, se modificar, tornar-se até certo ponto, outro que não ele mesmo, para que tivesse acesso à verdade; 3 ) a verdade apenas seria dada ao sujeito por certo preço, que pusesse em jogo o ser mesmo do sujeito, que afetasse esse mesmo sujeito. Doravante, era entendido que não poderia haver verdade sem uma "conversão" a si mesmo, ou transformação do sujeito, por meio de duas direções: a primeira seria um movimento de éros (amor), no qual a verdade viria até o sujeito e o iluminaria; a segunda estaria pautada num movimento de áskesis, entendido como um labor, um trabalho de si para consigo; em que se é o próprio responsável por seus pensamentos e ações (FOUCAULT, 2010a).

Era fundamental ao cuidado de si a constituição do indivíduo como sujeito, e para tanto, tais trabalhos eram balizados por princípios que se impunham como condições. Princípios e limites que, ainda que não fossem eternos, também não poderiam ser mudados de qualquer forma ou a qualquer momento. Ou seja, a reconstrução da moral greco-romana que Foucault (2009a, 2009b) propõe nos livros $O$ uso dos prazeres (1984) e $O$ cuidado de si (1985), mostra um tipo de relação do homem consigo mesmo que não se baseava nem na universalidade de um fundamento, tampouco numa reflexão sistemática sobre o sujeito como algo preexistente, como um dado prévio à experiência e à ação.

Nesse sentido, é preciso entender que a moral grega respeitava o caráter individual da conduta: a escolha do modo de vida era uma questão pessoal e a elaboração, o trabalho sobre a própria vida, apoiava-se em uma série de técnicas (techne tou biou) que não tinham caráter normativo, tampouco pretendiam se organizar em formato de códigos a serem seguidos. O elemento sobre o qual descansava a moral antiga era o trabalho sobre si, a ascética elevada à categoria de matriz constitutiva do êthos - a qual implicava relação do indivíduo consigo mesmo, relação com os outros e a relação com a verdade (GOMES, 2013).

Esta constatação converte a estética da existência em um modo de ver a ética, que tem como características a crítica e a experimentação: os sujeitos refletiam sobre suas práticas e condutas, associavam essas reflexões às suas atividades realizadas diariamente e, além disso, buscavam uma transformação de si mesmo. Ou seja, o trabalho estético era atravessado pelo exercício de buscar relações do sujeito consigo mesmo, o que tornava o princípio do cuidado de si fundamental para um conhecimento de si: o indivíduo não poderia mudar seu modo de ser no mundo sem alterar seu êthos (FOUCAULT, 2009b).

Alguns séculos depois, no período helenístico-romano (I-II d.C.), Foucault destaca que a noção do cuidado de si passou a assumir uma espécie de "acontecimento no pensamento", uma cultura de si:

Temos, pois, com o tema do cuidado de si, uma formulação filosófica precoce, por assim dizer, que aparece claramente desde o século V a.C. e que até os séculos IV-V d.C. percorre toda a filosofia grega, helenística e romana, assim como a espiritualidade cristã. Enfim, com a noção de epiméleia 
heautoû, temos todo um corpus definindo uma maneira de ser, uma atitude, formas de reflexão, práticas que constituem uma espécie de fenômeno extremamente importante, não somente na história das representações, nem somente na história das noções ou das teorias, mas na própria história da subjetividade ou, se quisermos, na história das práticas da subjetividade (FOUCAULT, 2010a, p. 12).

Por conseguinte, uma cultura de si deveria atender a um conjunto de valores que tivessem, entre si, coordenação, subordinação e hierarquia. Valores que fossem universais, mas não acessíveis a qualquer um; para atingir esses valores, os indivíduos deveriam realizar certas condutas, precisas e regradas. Por fim, era preciso que o acesso a esses valores fosse condicionado por técnicas e procedimentos regrados, que tivessem sido elaborados, validados, transmitidos e associados a um conjunto de noções, conceitos e teorias, a todo um campo de saber.

Muitas características desse acontecimento no pensamento nos são apresentadas à medida que os escritos foucaultianos mergulham em textos antigos. A primeira delas se baseia na presença marcante da noção de epiméleia heautô̂ em doutrinas filosóficas antigas. Textos de Epicuro, como Carta a Meneceu, interligavam o cuidado de si ao cuidado com a própria alma, à atividade de filosofar e a busca da felicidade: um cuidado que ninguém, sendo jovem ou velho, deveria desconsiderar - aqueles que quisessem salvar suas almas e alcançar a felicidade, deveriam viver cuidando-se sem cessar (FOUCAULT, 2009c).

Entretanto, essa atividade de ter cuidado com a própria alma, em todos os momentos da vida, apresentava uma particularidade: quando se era jovem tratava-se de preparar-se para a vida, equiparar-se para a existência - configurando o que os antigos entendiam por paraskheué; ${ }^{3}$ e no caso da velhice, filosofar era rejuvenescer, voltar ao tempo ou desprender-se dele através de atividades de memorização.

Havia ainda os exames de consciência que faziam parte dos ensinamentos pitagóricos, caracterizados por exercícios de memorização. Destacam-se dentre esses exames, os exames da manhã (nos quais o sujeito elencava em sua mente as tarefas que deveriam ser realizadas ao longo do dia) e os exames da noite (baseado num exercício de memorização daquilo que ocorreu e o que poderia ter acontecido durante o dia transcorrido).

Em Sêneca, Foucault destaca uma amplitude tomada pelo tema da aplicação a si próprio: para consagrar o cuidado de si era preciso renunciar às outras ocupações. Considera ainda que Sêneca dispunha de todo um vocabulário para designar as diferentes formas que o cuidado de si deveria tomar, de modo que não houvesse perda de tempo, e que esforços não fossem poupados a fim do sujeito formar-se, transformar-se, voltar a si mesmo. Em Marco Aurélio, sinaliza essa mesma pressa do sujeito em ocupar-se

\footnotetext{
${ }^{3}$ Trata-se de montar um mecanismo de segurança, não de inculcar um saber técnico e profissional ligado a um determinado tipo. Essa formação, essa armadura se quisermos, armadura protetora em relação ao resto do mundo, a todos os acidentes ou acontecimentos que possam produzir-se, é o que os gregos chamavam de paraskheué (FOUCAULT, 2010a, p. 86).
}

consigo, ao passo que nem a escrita nem a leitura deveriam afastar as pessoas dos cuidados diretos que deveriam ter para com suas próprias existências (FOUCAULT, 2009c).

Em Epicteto, Foucault assegura encontrar a mais alta elaboração filosófica sobre o cuidado de si, uma vez que nos seus Diálogos o ser humano aparece como o ser a quem foi confiado o cuidado de si, marcando uma diferença em relação aos outros seres vivos: os outros animais têm tudo pronto no que concerne ao que lhes é necessário para sobreviver; já o homem deve velar por si mesmo, porque Zeus quis que o mesmo pudesse, livremente, fazer uso de si próprio. Assim sendo: "O cuidado de si, para Epicteto, é um privilégio-poder, um dom-obrigação que nos assegura a liberdade obrigando-nos a tomar-nos nós próprios como objeto de toda a nossa aplicação" (FOUCAULT, 2009c, p. 53).

A pesquisa histórica que Foucault (2010a) apresenta no curso de 1982 ( A hermenêutica do sujeito) nos faz entender ainda que os princípios do cuidado de si serviam para medir e confirmar a independência do que se era capaz a respeito de tudo o que não fosse indispensável e essencial à vida: serviam, àqueles que os seguissem, a familiarizar-se com o mínimo.

Outro aspecto, não menos importante, do cuidado de si consistia numa certa forma de atenção, de olhar, de converter o olhar do exterior para si mesmo - implicando certa maneira de estar atento ao que se pensa e ao que se passa no pensamento. Ademais, epiméleia heautô̂ poderia ser considerado um labor em meio a um conjunto de ocupações: sejam as atividades como dono de casa, as tarefas do príncipe que vela seus súditos, os cuidados destinados aos enfermos, ou mesmo, as obrigações para com os deuses. Para Foucault (2009c, p. 56-57):

Ocupar-se de si não é uma sinecura. Existem os cuidados com o corpo, os regimes de saúde, os exercícios físicos sem excesso, a satisfação, tão medida quanto possível, das necessidades. Existem as meditações, as leituras, as anotações que se toma sobre livros ou conversações ouvidas, e que mais tarde serão relidas, a rememoração das verdades que já se sabe, mas de que convém apropriar-se ainda melhor. [...] Em torno dos cuidados consigo toda uma atividade de palavra e de escrita se desenvolveu, na qual se ligam o trabalho para consigo e a comunicação para com outrem.

Essas provações, exercícios e exames preconizavam um cuidado de si balizado por certo modo de estar no mundo, uma atitude para consigo, para com os outros, para o mundo: epiméleia heautô̂ como ações exercidas de si para consigo, pelas quais nos assumimos, nos modificamos, nos transfiguramos.

\section{Ética e liberdade no cuidado de si}

Além das práticas de si que implicavam numa constituição estética da existência, Foucault ressalta que uma das principais preocupações na Antiguidade grega eram as técnicas de subjetivação - entendidas a partir do modo em que se dariam a formação dos jovens, a construção de si, bem como a busca de uma vida temperante $^{4}$ e digna de ser vivida.

${ }^{4} \mathrm{Na}$ busca por uma vida temperante, colocava-se em questão o equilíbrio que cada 
A partir da problematização dessas técnicas, Foucault elabora um pensar sobre certa noção de moral que desconhecia o sujeito, uma moral que não quisesse proporcionar um assujeitamento: uma experiência moral que não estivesse centrada na figura do sujeito, bem como na relação específica que ele estabelece com a verdade. Porém, o levante dessa problemática não implicava em vislumbrar na moral antiga um modelo a ser seguido, mas apenas perceber como foi possível uma configuração de pensamento moral tão distanciado daquilo que vivemos na contemporaneidade:

Ora, creio que uma experiência moral essencialmente centrada no sujeito não é mais satisfatória atualmente. E, por isso mesmo, um certo número de questões se coloca hoje para nós nos mesmos termos em que elas se colocavam na Antiguidade. A busca de estilos de vida, tão diferentes quanto possíveis uns dos outros, me parece um dos pontos pelos quais a busca contemporânea pôde se inaugurar antigamente em grupos singulares. A busca de uma forma de moral que seria aceitável por todo mundo - no sentido de que todo mundo deveria submeter-se a ela - me parece catastrófica (FOUCAULT, 2006, p. 262-263).

Vale lembrar que, para Foucault, a noção de "sujeito" remete à ideia moderna de assujeitamento: a produção do sujeito por meio das práticas de dominação e normatização. Por outro lado, nas civilizações greco-romanas antigas, o que se tinha era produção de subjetividade, enquanto modos de constituição de si. Em entrevista a Alessandro Fontana, em julho de 1984 ao jornal Le Monde, Foucault (2006, p. 291) nos diz:

Em primeiro lugar, penso efetivamente que não há um sujeito soberano, fundador, uma forma universal de sujeito que poderíamos encontrar em todos os lugares. Sou muito cético e hostil em relação a essa concepção do sujeito. Penso, pelo contrário que o sujeito se constitui através das práticas de sujeição ou, de maneira mais autônoma, de práticas de liberação, de liberdade, como na Antiguidade - a partir, obviamente, de um certo número de regras, de estilos, de convenções que podemos encontrar no meio cultural.

Entre os séculos IV e II a.C., no berço das noções de autonomia e democracia ateniense, as práticas de construção da subjetividade entendiam que cada sujeito era capaz de produzir suas próprias verdades, uma vez que estas eram provenientes da relação de si para consigo, mediadas pela temperança e pela justa medida. O exercício cívico, ético e político em questão era o conhecer-se, converter o olhar para si mesmo, reconhecer seus limites, transformar-se e sentir-se livre por não ser dominado nem pelos outros e nem por si próprio. Em meio a esse movimento ético e político de postar-se consigo e com os outros, o cuidado de si articula-se ao exercício político e às práticas cotidianas de liberdade, proporcionando aos sujeitos possibilidades de compor para si mesmos determinados modos de vida, experienciar (transformando o sujeito) e regrar suas condutas (GOMES, 2013).

\footnotetext{
indivíduo deveria ter em relação ao uso dos prazeres, jamais sendo entendida como qualquer espécie de renúncia àquilo que se deseja. A ideia de renúncia aos usos dos prazeres será uma das marcas da absorção feita pelo cristianismo perante a experiência ética greco-romana.
}

Nesse passeio pela Antiguidade, ao mesmo tempo em que a tessitura dos escritos foucaultianos nos leva a pensar em modos de vida como uma obra de arte, numa ética atrelada à estética da existência, também atravessa um campo de problematizações e enunciados de ordem moral, construído por meio de interdições e códigos de conduta. Como exemplo, têm-se as apropriações morais da ascese cristã pelos códigos morais da ascese antiga, as quais se configurariam, a partir do século VI da nossa era, em morais integradas aos saberes pedagógico, médico, psicológico:

[...] na Antiguidade, a vontade de ser um sujeito moral, a busca de uma ética da existência eram principalmente um esforço para afirmar a sua liberdade e para dar a sua própria vida uma certa forma na qual era possível se reconhecer, ser reconhecido pelos outros e na qual a própria posteridade podia encontrar um exemplo. [...] Da Antiguidade ao cristianismo, passa-se de uma moral que era essencialmente a busca de uma ética pessoal para uma moral como obediência a um sistema de regras (FOUCAULT, 2006, p. 289-290).

Em algumas passagens do segundo tomo da História da sexualidade, o termo "moral" faz menção tanto a um conjunto de valores e regras de ações propostas aos indivíduos ou grupos por aparelhos prescritivos, quanto ao modo pelo qual os indivíduos podiam se submeter, obedecer ou resistir, respeitar ou negligenciar esse mesmo conjunto de regras prescritivas. A cultura de si grega não era uma moral da lei e do preceito geral, mas uma ética da pluralidade de normas e de escolha de modos de vida:

[...] uma coisa é uma regra de conduta; outra, a conduta que se pode medir a essa regra. Mas, outra coisa ainda é a maneira pela qual é necessário 'conduzir-se' - isto é, a maneira pela qual se deve constituir a si mesmo como sujeito moral, agindo em referência aos elementos prescritivos que constituem o código. Dado um código de ação, e para um determinado tipo de ação (que se pode definir por seu grau de conformidade ou de divergência em relação a esse código), existem diferentes maneiras de 'se conduzir' moralmente, diferentes maneiras, para o indivíduo que age, de operar não simplesmente como agente, mas sim como sujeito moral dessa ação (FOUCAULT, 2009b, p. 34).

Quando Foucault nos diz das possibilidades de um indivíduo conduzir-se moralmente, quer, a partir disso, marcar a proximidade que enxerga entre moral e ética: conduzir-se moralmente implicava, ao mesmo tempo, em uma relação ética consigo mesmo, uma vez que toda ação moral repercutia numa ação sobre si, estabelecia para si certo modo de ser que valeria como realização moral dele mesmo. O sujeito passava a agir sobre si mesmo, procurando conhecer-se, controlar-se, pôr-se a prova, aperfeiçoar-se, transformar-se:

Em suma, para ser dita 'moral' uma ação não deve se reduzir a um ato ou a uma série de atos conformes a uma regra, lei ou valor. É verdade que toda ação moral comporta uma relação ao real em que se efetua, e uma relação ao código a que se refere; mas ela implica também uma certa relação a si; essa relação não é simplesmente 'consciência de si', mas constituição de si enquanto 'sujeito moral', na qual o sujeito circunscreve a parte dele mesmo que constitui o objeto dessa prática moral [...]. Não existe ação moral particular que não 
se refira à unidade de uma conduta moral; nem conduta moral que não implique a constituição moral de si mesmo como sujeito moral; nem tampouco constituição do sujeito moral sem 'modos de subjetivação', sem uma 'ascética' ou sem 'práticas de si' que as apoiem (FOUCAULT, 2009b, p. 37).

Em meio a essas colocações sobre o que entende por "moral", Foucault elabora quatro aspectos que veem a constituir à sua compreensão sobre o termo "ética": 1) "determinação da substância ética", que aponta a maneira pela qual o indivíduo devia constituir-se como matéria principal de sua conduta moral; 2) "modo de sujeição" pelo qual o indivíduo estabelecia sua relação com essa regra, reconhecendo-se na obrigação de pô-la em prática; 3 ) as formas de "elaboração do trabalho ético" que efetuava sobre si mesmo, não somente para tornar seu próprio comportamento conforme a uma regra dada, mas para tentar transformar a si mesmo em sujeito moral de sua própria conduta; 4) "teleologia" do sujeito moral, que era a forma de subjetividade almejada, haja vista que uma ação não era moral em si mesma e na sua singularidade, mas na sua inserção e no lugar que ocupava no conjunto de uma conduta (FOUCAULT, 2009b).

Vê-se que a complexidade das relações morais e éticas situava-se num entre a constituição de códigos morais, através da prescrição de valores e regras que podiam estar representados a partir de instituições que os legitimassem ou mesmo circulassem em formas discursivas (os ditos e os não-ditos), bem como aos modos pelos quais os indivíduos podiam tornar-se sujeitos a estes códigos morais ou resistir aos mesmos. Por outro lado, essas relações também possuíam uma orientação ética, cujo elemento forte e dinâmico situava-se ao lado das formas de subjetivação e das práticas de si, sendo enfatizadas as formas das relações consigo, os procedimentos e as técnicas pelas quais eram elaboradas, os exercícios de conversão do olhar para si mesmo, e práticas que permitiam a modificação de si.

Para além dos laços que circunstanciavam a constituição e elaboração do êthos (ou seja, a maneira que o sujeito tinha de ser, de conduzir-se, de se fazer visível para os outros) a relação ética do sujeito implicava ainda em um sentir-se livre, tomando o sentido de liberdade (ou práticas de liberdade) como a condição ontológica da ética, e sendo a ética a forma refletida assumida pela liberdade. Segundo Foucault: "O cuidado de si constituiu, no mundo greco-romano, o modo pelo qual a liberdade individual - ou a liberdade cívica, até certo ponto - foi pensada como ética" (FOUCAULT, 2006, p. 268).

Nessa relação entre liberdade, ética e cuidado de si, a liberdade era entendida como uma prática na qual o sujeito não poderia sentir-se dominado pelos outros e nem por si mesmo, e, para tanto, para o bem dessas práticas de liberdade, se fazia necessário ocupar-se de si mesmo, cuidar de si, ao mesmo tempo para conhecer-se e dominar os apetites que poderiam, por ventura, extasiar esse mesmo sujeito. Para Foucault (2006, p. 268; 270):

[Na Antiguidade] Temos toda uma ética que girou em torno do cuidado de si e que confere à ética antiga sua forma tão particular. Não digo que a ética seja o cuidado de si, mas que, na Antiguidade, a ética como prática racional da liberdade girou em torno desse imperativo fundamental: 'cuida-te de ti mesmo'. [...] O êthos de alguém se traduz pelos seus hábitos, por seu porte, por sua maneira de caminhar, pela calma com que responde a todos os acontecimentos etc. Esta é para eles a forma concreta da liberdade; assim eles problematizavam sua liberdade. $\mathrm{O}$ homem que tem um belo êthos, que pode ser admirado e citado como exemplo, é alguém que pratica a liberdade de uma certa maneira.

A relação entre cuidado de si, liberdade e ética, aludia, doravante, uma inseparabilidade entre a ética do cuidado de si e o governo político dos outros: como as pequenas e mais simples práticas que caracterizavam o cuidado ético dos sujeitos, o exercício constante de conhecer-se, repercutiam em ações amplificadas de cuidar dos outros? Como o cuidado de si alcançava um gerenciamento (político) dos outros na Antiguidade? Além disso, mediando suas diferenças, em que medida o cuidado de si pode oferecer ferramentas analíticas de discussão e enfrentamento da conjuntura política atual?

\section{A dimensão política do cuidado de si}

A semelhança entre as dimensões políticas e éticas do cuidado de si é uma postura ativa, uma inquietação daquele que se propõe a por em prática os exercícios do cuidado, tanto no governo de si (atenção para consigo), quanto para com os outros: o cuidado de si passa a ser uma ferramenta que permite reatravessar o campo da política (problema da estruturação das condutas dos outros), a partir da problematização da ética (problema da estruturação da relação consigo).

Para endossar essa questão, façamos alusão a dois textos detalhadamente apresentados por Foucault (2010a, 2010b) em seus últimos cursos no Collège de France, a saber: o "Primeiro Alcibíades", de Platão, exposto no curso A hermenêutica do sujeito de 1982, e a "Apologia de Sócrates", abordado no curso O governo de si e dos outros de 1983.

No texto "Primeiro Alcibíades", tinha-se como questão primeira o desejo do jovem Alcibíades em desfrutar do privilégio político do governo da cidade de Atenas, uma vez que o mesmo pretendia fazer uso do seu status privilegiado da descendência aristocrática. Eis que neste diálogo platônico surge o personagem Sócrates, o qual se dizia incumbido pelos deuses em interpelar as pessoas acerca do exercício do cuidado de si e, ao mesmo tempo, renunciara sua própria carreira política para incitar os outros a cuidarem de si mesmo - daí que o cuidado de si faz analogia a um despertar, e o personagem de Sócrates à figura de um tavão 5 (GOMES, 2013).

Sócrates dirige-se a Alcibíades e o intento desse diálogo é lembrar que o bom exercício do governo (dos outros) - dimensão política do governo - teria, como condição primeira, o exercício do cuidado de si mesmo. Por conseguinte, Alcibíades não se encontrava preparado para o exercício da arte de governar: ignorava a téckne necessária daquilo que deveria saber; pretendia governar a cidade, mas não sabia como fazê-lo, nem tampouco a finalidade da atividade política.

${ }^{5}$ Inseto que persegue os animais, pica-os e os faz correr e agitar-se. Nesse sentido, o cuidado de si se relaciona a um princípio de inquietação da existência. 
Paralelamente, outras questões significativas à narrativa passam a ser fundamentadas dentro desse diálogo. Por exemplo, o fato de Sócrates interessar-se por Alcibíades, mesmo quando este já se encontrava no limiar da juventude (não tão belo quantos muitos outros jovens que interessam a Sócrates), e, por outro lado, ambicionava o exercício do governo, indica uma denúncia platônica à educação ateniense, que se encontrava decadente em comparação às práticas pedagógicas desenvolvidas, na mesma época, em Esparta e pelos povos orientais (mais especificamente, os persas). Destarte, a crítica socrática destaca este momento em que o jovem Alcibíades não se encontra amparado pela educação ateniense - quando mais precisava ser conduzido (cuidado e/ou governado) pelos pedagogos (GOMES, 2013).

Quando Alcibíades estava no auge da sua juventude, seus pretendentes visavam apenas à beleza de seu corpo e, à medida que tempo passava, não destinavam cuidado necessário ao seu bem viver. Por outro lado, Sócrates se interessa em governar a alma ${ }^{6}$ de Alcibíades, para que este pudesse aprender a cuidar de si próprio, bem como exercitar, devidamente, o governo dos outros.

Percebe-se no texto do "Primeiro Alcibíades" que a importância do cuidado de si fazia-se como condição fundamental para o governo político dos outros: Alcibíades é lembrado a todo instante que as práticas governamentais devem ser antecedidas do controle de suas vontades. Sócrates conclui que Alcibíades teria tempo para aprender a governar a cidade, alertando-o que na cultura do cuidado de si, governar a cidade, governar os outros, pressupõe certa prudência: para que o governante seja capaz de cuidar de si mesmo, precisa olhar para si, converter o olhar para si mesmo e encontrar em si sua verdade e sua justiça. Segundo Foucault (2010a, p. 76-77):

[...] a finalidade do cuidado de si, não o objeto, era outra coisa. Era a cidade. Sem dúvida, na medida em que quem governa faz parte da cidade, também ele, de certo modo, é finalidade de seu próprio cuidado de si e, nos textos do período clássico, encontra-se com frequência a ideia de que o governante deve, como convém, aplicar-se a governar, para salvar a si mesmo e a cidade - a si mesmo enquanto parte da cidade. [...] A cidade mediatizava a relação de si para consigo, fazendo com que o eu pudesse ser tanto objeto quanto finalidade, finalidade contudo unicamente porque havia a mediação da cidade.

Um segundo texto analisado por Foucault para contemplar essa relação política entre o cuidado de si e o governo dos outros, é a "Apologia de Sócrates", presente no curso de 1983. Este texto traz os momentos que antecedeu o julgamento de Sócrates, destacando o descrédito socrático em relação à instituição política ateniense. Ou seja, como Sócrates se apresentava como o homem do dizer-a-verdade (aquele que exercia o franco-falar, a parresía), ao passo que caracterizava seus acusadores e adversários como aqueles que nunca disseram senão coisas falsas, esse texto marca uma situação, para Sócrates,

\footnotetext{
${ }^{6} \mathrm{~A}$ alma (psyché) indica o eu como objeto do cuidado. No "Primeiro Alcibíades", Platão toma distância da noção de alma como pertencente ao corpo, encontrada mais tarde no Fédon ou na República. Que o sujeito seja sua alma significa postulá-lo como sujeito de ação (FOUCAULT, 2010a).
}

na qual se fazia fundamental praticar a parresía, ao mesmo tempo em que era um momento muito perigoso para exercê-la, uma vez que a parresía filosófica se colocava em seu ponto de conflito mais agudo: conflito de vida ou morte, com a eloquência político-judiciária tradicional (FOUCAULT, 2010b).

Aqui, é importante abrir um parêntese para explicar brevemente o sentido e o significado do franco-falar, ou parresía, na Antiguidade - apresentado por Foucault desde as últimas aulas do curso precedente, $A$ hermenêutica do sujeito. Falar com parresía nada mais seria do que falar sem nada ocultar, nem dissimular. Além disso, o termo podia ser empregado em dois sentidos: o pejorativo, no qual se dizia tudo, não importando o que, sem princípio de racionalidade ou de verdade, como na "má cidade democrática"; já o sentido positivo consistia em dizer a verdade sem reserva, nem retórica: dizer tudo, sim, desde que relacionado diretamente à verdade, sem mascará-la. Para caracterizar este sentido positivo, Foucault cita duas condições suplementares: o sujeito, ao dizer o que pensa, corre o risco de irritar o outro, arrisca-se à violência, fazendo com que a parresía demande certa forma de coragem, a coragem para se falar a verdade (FOUCAULT, 2010b).

Nesse sentido, uma aplicação da parresía é propor às funcionalidades políticas ações arriscadas e indeterminadas, uma vez que o dizer-verdadeiro, a pretensão de verdade enunciada em uma assembleia, pressupõe uma força, uma potência, uma ação sobre si que implica na coragem de dizer aquilo que lhe é verdadeiro, e uma ação sobre os outros para guiar e dirigir condutas. É nessa linha de pensamento que Foucault nos diz sobre a diferenciação ética de um processo de singularização desencadeado por meio da enunciação parresiástica: a parresía provoca que os sujeitos políticos se constituam a si mesmos enquanto sujeitos éticos, capazes de se arriscar, lançar um desafio, que sejam capazes de governar a si mesmo e aos outros (GOMES, 2013).

Para o Sócrates que Foucault nos descreve, o cuidado de si estaria vinculado a um estilo de vida alternativo em relação à atividade política institucional, assemelhando-se no texto da "Apologia", ao cuidado da verdade uma vez que Sócrates preferiu manter-se fiel àquilo que pensava ser verdade, desafiar seus adversários, e nem ao menos propôs alguma pena alternativa ao seu julgamento, mesmo lhe sendo facultada essa possibilidade. Destarte, o cuidado da verdade fez-se presente no critério da proposta socrática da inversão de valores na sociedade ateniense, ao mesmo tempo em que será marcada uma diferença entre o exercício, destinado a Sócrates pelos deuses, do cuidado dos atenienses, e o cuidado proporcionado pela política institucional (FOUCAULT, 2010b).

Frédéric Gros (2004) faz uma elaboração interessante dessa relação entre cuidado da verdade e cuidado da vida, bem como a crítica da política ateniense, que Foucault formula dentro do estudo da filosofia socrática. Para Gros, isso não deixa de ser a apresentação vertical do próprio modo como Foucault pensava a política institucional, pelo menos a partir do final dos anos 1970 e início dos anos 1980, ainda que o contexto e as formas de proble- 
matização sejam bem diferentes. Comumente percebemos modos de governar contemporâneos que insistem na divulgação de discursos impositivos de verdades. Ou seja, discursos que convêm a tais modos de governar, que legitimem as próprias ações do governo. Assim, o grande desafio do cuidado de si inserido num contexto de exercício político, talvez seja sua relação com o cuidado da verdade, como o próprio Foucault (2006, p. 292) já anunciava em uma entrevista ao Le Monde, em julho de 1984:

[...] É claro que não se pode pedir a um governo para dizer a verdade, toda a verdade, nada a mais que a verdade. Em troca, é possível exigir dos governos uma certa verdade em relação aos projetos finais, às escolhas gerais de sua tática, a um certo número de pontos particulares de seu programa: é a parrhesia (a livre fala) do governado que pode, que deve interpelar o governo em nome do saber, da experiência que ele tem, a partir do fato de que ele é um cidadão, sobre o que o outro faz, sobre o sentido de sua ação, sobre as decisões que ele tomou.

Considerando que a maioria dos enunciados que tratam de gerir e cuidar das vidas, principalmente no decorrer do século XX, estão assentados em dispositivos de verdade de caráter político (por vezes, eleitoreiro), Foucault (2008, p. 13) já nos alertava que o problema não é mudar a "consciência" das pessoas, ou aquilo que elas têm na cabeça, mas o regime político, econômico, institucional de produção da verdade:

Há um combate 'pela verdade' ou, ao menos, 'em torno da verdade' - entendendo-se, mais uma vez, que por verdade não quero dizer 'o conjunto das coisas verdadeiras a se descobrir ou a fazer aceitar', mas 'o conjunto das regras segundo as quais se distingue o verdadeiro do falso e se atribui ao verdadeiro efeitos específicos de poder'; entendendo-se também que não se trata de um combate 'em favor' da verdade, mas em torno do estatuto da verdade e do papel econômico-político que ela desempenha.

Por conseguinte, dispositivos de verdade de ações políticas atuais sustentam o discurso de governar em nome da vida, do seu cuidado e conservação, na busca de uma "qualidade de vida" e longevidade, refletindo o sentido de uma biopolítica (política em nome da vida / fazer viver). Todavia, tais dispositivos operam, ao mesmo tempo, a partir de uma crescente dependência da vida à administração e ao controle de um biopoder (vida submissa ao comando da política / política sobre a vida / deixar morrer).

Na contramão deste movimento, podemos encontrar no cuidado filosófico de dizer verdade um modo de enfrentamento em relação a tais ações políticas, haja vista que esse cuidado remete a uma dimensão ética, bem como à liberdade do sujeito. Quando Foucault (2006, p. 264-287) articula cuidado de si / ética / liberdade na entrevista intitulada A Ética do Cuidado de Si como prática da liberdade, pontua que não existe uma liberdade que seja algo "natural" do ser humano, ou que ser livre não se limita a agir sem impedimentos externos, sem a coerção do poder público ou de outra natureza. A liberdade é entendida como efeito de ações que podem tanto limitar o campo de possibilidade de outras ações, como também não se deixar determinar inteiramente por elas. Depre- ende-se a afirmação foucaultiana de que não existe "a" liberdade, mas práticas de liberdade que podem criar e produzir modos de se governar, como também limitar e resistir ao governo dos outros (GOMES, 2013).

\section{Considerações finais}

As relações do sujeito para com os jogos de produção de verdade, seja por meio da análise dos discursos científicos ou práticas institucionalizadas e coercitivas, são pontos incisivos nos escritos de Michel Foucault, e ainda carregam problematizações bastante atuais. Nos estudos das civilizações grega e romana, toda elaboração do pensamento em torno das práticas e do cuidado de si, não veio a destoar do conjunto das relações de poder exercidas entre indivíduos.

Aquele que cuida de si, dos seus afazeres, das suas funções enquanto dono de casa, como esposo ou pai, saberá manter as relações adequadas e prudentes para com seus entes próximos. Numa mesma proporção, as relações nos jogos políticos para com os outros serão estabelecidas pela justa medida: aquele que se encarregar de cuidar dos outros saberá a dimensão exata do exercício do seu poder, sem abusos ou negligências, coerções ou desperceber as mazelas da população.

Nesse sentido, é a partir desse trato ético despertado pelo cuidado de si nas relações dos sujeitos, para consigo e para com os outros, que Foucault apresenta um sujeito ético-político de postura ativa, cujas práticas não passam de esquemas que este mesmo sujeito encontra em sua cultura, e que lhe são propostos, sugeridos por sua sociedade e seu grupo social. Assim, um cuidado ético e político para consigo e os demais pode, e deve, se fazer presente e em possibilidades de traçar caminhos juntos, em prol de uma coletividade. Entretanto, incumbe a todo e qualquer sujeito a busca de uma postura ativa, assumindo o risco ao exigir respaldos éticos, pedagógicos, bem como ontológicos nas relações políticas contemporâneas.

\section{Referências}

FOUCAULT, M. Ética, Sexualidade, Política. Rio de Janeiro: Forense Universitária, 2006. Coleção Ditos \& Escritos, v. 5.

FOUCAULT, M. Microfisica do poder. Rio de Janeiro: Graal, 2008.

FOUCAULT, M. História da Sexualidade: a vontade de saber. Rio de Janeiro: Graal, 2009a. v. 1.

FOUCAULT, M. História da Sexualidade: o uso dos prazeres. Rio de Janeiro: Graal, 2009b. v. 2.

FOUCAULT, M. História da Sexualidade: o cuidado de si. Rio de Janeiro: Graal, 2009c. v. 3.

FOUCAULT, M. A hermenêutica do sujeito. São Paulo: WMF Martins Fontes, 2010a.

FOUCAULT, M. O governo de si e dos outros. São Paulo: WMF Martins Fontes, 2010b.

GOMES, M. M. O. O cuidado de si na redução de danos: uma análise histórica, política e ética, a partir de Michel Foucault. 2013. Dissertação (Mestrado em Psicologia Social) Universidade Federal de Sergipe, São Cristóvão, 2013.

GROS, F. A coragem da verdade. São Paulo: Parábola, 2004.

Recebido em: 15 de setembro de 2015

Aceito em: 18 de agosto de 2017 